AC 2011-2152: THE IDENTIFICATION AND EMERGENCE OF CONSTRAINTS IN ENGINEERING DESIGN PROJECTS

Andrea Goncher, Virginia Tech

Andrea Goncher is a Ph.D. candidate in Engineering Education at Virginia Polytechnic and State University.

Dr. Aditya Johri, Virginia Tech

(c)American Society for Engineering Education, 2011 


\title{
The Identification and Emergence of Constraints in Engineering Design \\ Projects
}

\begin{abstract}
The focus of this paper is on how constraints are identified within design teams and how the context of each constraint or a set of constraints shape team design solutions as well as the design development over the course of the project. Design is generally constrained by nature, cost, safety, reliability, etc. and the role of these constraints varies based on the context of the design project as well as the objectives of the design prompt. The identification and evaluation of these constraints differentiates design from conventional optimization when determining or selecting a solution and is an important aspect in studying how solutions evolve throughout the design process. Through an observational study of 4 design teams within the context of a course design project, we differentiate and describe constraints imposed by the design project and how constraints emerged as teams solved design problems. We found differences in how constraints affected the final design solutions that were based on whether teams identified them in the conceptual phase, i.e. appropriated constraints, versus constraints that emerged through team interaction and project materialization. By understanding how teams identify and leverage constraints throughout the design process and apply constraints in design situations has several implications for team learning and knowledge sharing for good conceptual design thinking and meeting design objectives.

Introduction

The broad academic discussion regarding design spans many domains and disciplines including science, engineering, psychology, and education. Not only is design the distinguishing feature of engineering ${ }^{1}$ but it is also a focus in education due to its creative and practical applications of knowledge ${ }^{2}$. Subsequently, engineering education emphasizes the design of systems, components, or processes as part of engineering experience ${ }^{3}$. The National Academy of Engineering ${ }^{4}$ defines engineering as "design under constraint", the creation and design of "what can be" constrained by nature, cost, safety, reliability, environmental impact, manufacturability, maintainability, and many others. However the realities of design are inherently complex, leading many studies to focus on specific stages of the design process. For example brainstorming and ideation are steps in the design process used to explore solution space; consequently the element of constraint becomes important as designers begin their search of the solution space.

Constraints in Design

Inherent to the nature of design, designers face limits within their search of the solution space. Constraints, which are clearly defined limits that shape the size of the design space ${ }^{5}$ can be
\end{abstract}


nomological or social ${ }^{6}$ or conceptual or physical ${ }^{7}$. These features of design emerge from design requirements and/or arise from the knowledge and experiences of the designer ${ }^{8}$. The role of constraints is important to the study of the solution space because of their influence on decision making and thought processes as designers work within the problem frame.

Evaluating and selecting novel or optimal constraints differentiates design from conventional optimization $^{9}$. Constraints ultimately shape and reduce the complexity solution ${ }^{5.10}$ giving designers an opportunity to reevaluate the universe of solutions based on goal attainment. Designers use constraints to minimize or reduce the complexity of the design problem and the application is implicit to authentic design tasks. In this paper we study how student engineering teams identify and evaluate the topology of constraints in the context of an engineering course project.

Research Questions

Specifically, the following research questions have been investigated while studying the role of constraints in the design process.

- What do students identify as the context and nature of a constraint?

- What cues or major issues or constraints do students use to facilitate design solutions?

We addressed each of these questions utilizing data obtained from 4 student design teams as they progressed from ideation to functioning prototype for a freshman level engineering course project. Through this research, we have identified several categories of constraints and how they shaped the final design solution.

Setting and Data Collection

The context for this research is a foundational engineering course for freshman engineering students not enrolled in a specific engineering discipline. The engineering students in this course developed "innovational solutions" to highlight the usefulness and effectiveness of renewable energy. One definitive constraint imposed on every group was a budget constraint for constructing the final design. Also for all engineering design teams, one or more key components of a renewable energy source were required for the design; the design was also encouraged to educate, entertain, and generate further inquiry into creative renewal energy solutions.

Participants in this study were part of both a large lecture course and a smaller related workshop; each with a heavy design focus in the curriculum. While students were not specifically instructed on teaming practices, engineering design team activities were part of the weekly workshop. The teams participating in this study formed based on mutual team member availability but did not preserve the same team for the other engineering design activities that took place during the workshops. The design project did not heavily structure explicit teaming experience but the structure of the project guided the students through the steps of the design process. Workshop 
instructors presented the overall design project at the introduction of the project and design artifacts were collected from each team at 5 phases of the process: problem definition, information gathering, ideation, solution analysis, and testing and implementing the solution. While several participants indicated prior experience regarding design and teamwork, studying freshman level engineering design teams allows us to investigate the impact of engineering design activities and constraints before the effects of specific disciplinary knowledge and subsequently the way they interact with constraints.

Teams were observed on a weekly basis through individual team meetings as well as in-class presentations with the instructor/ evaluator present. Focus group/ debriefing interviews were also performed at the completion of the project and course to capture team member perceptions regarding their experience in both the project as well as the larger context of the course. The authors also had to reconstruct some content regarding team interaction outside of the class or design meetings by asking them about their recounts of these sessions. The composite of data collection for this study, included video observations of team meetings, focus group interviews, and written design artifacts. One limitation of this methodology is the consistency of the video data across the teams we studied. Teams were not required to meet outside of class or in a designated location. However we found that most teams tended to meet in a predetermined location around the time that the design deliverables were due for the course, enabling the researchers to video record their meetings and discussions.

\section{Data Analysis}

For this paper, we used a qualitative approach to begin addressing what design teams identified or perceived as constraints. Specifically, we used multi-case study methods to qualitatively and inductively study how and why teams used constraints to shape their final design. Video observations and interview sessions were transcribed and open coded for elements representing constraints as part of the design process. The video data of early team meetings were coded for constraints that arose as part of the conversation in ideation/ brainstorming sessions. We constructed an overall typology of constraints after the initial analysis of what teams, in general, identified as constraints when thinking of final design solutions. The general design constraints surrounding engineering design projects were categorized as Manufacturability, Health and Safety, Life Cycle, Ethical, Ergonomic, and Quality. Constraints that arose as part of this data mostly fell into one category; if an element coded as a constraint appeared to belong to more than one category it was included in both. The other levels of constraints grew from either the context of the course or the context of the project. These included, Project: Functional, Economic, Aesthetic, Sustainability, and Course: Prior Knowledge/ Experience, Timing, Technological, and Social.

Researchers completed the coding process in two phases. The coding scheme developed to investigate the nature of constraints associated with the design process was initially constructed using two coders. Initial coding began with transcriptions of the video data with timestamps of 
the activity. In addition the video transcriptions were coded for occurrences or discussion of both explicit constraints; i.e. instances that students identified as constraints, and underlying constraints that students encountered but did not explicitly identify. Each coder watched the team design sessions and coded for the types of constraints that were present in the data. Both coders then compared the types of constraints they found in the data and created a compiled and categorized list of constraint codes. In the second phase of the coding process one coder used the finalized coding scheme to recode the video observation data. Table 1 illustrates the complete coding matrix used to evaluate the video data.

Table 1. Constraint Codes

\begin{tabular}{|c|c|c|}
\hline & Code & Explanation \\
\hline \multicolumn{3}{|l|}{ Design Constraints } \\
\hline Manufacturability & $\mathrm{DC} / \mathrm{M}$ & Ease of manufacturability of final design \\
\hline Health \& Safety & DC/HS & $\begin{array}{l}\text { Health and safety of end users engaging with final } \\
\text { design }\end{array}$ \\
\hline Life Cycle & $\mathrm{DC} / \mathrm{LC}$ & Life cycle concerns of final design \\
\hline Ethical & $\mathrm{DC} / \mathrm{E}$ & Ethical considerations associated with final design \\
\hline Ergonomic & DC/ERG & $\begin{array}{l}\text { Ergonomic considerations associated with final design } \\
\text { and end users }\end{array}$ \\
\hline Quality & $\mathrm{DC} / \mathrm{Q}$ & Overall quality of final design \\
\hline Functionality & $\mathrm{DC} / \mathrm{F}$ & Degree of the functioning or working final design \\
\hline \multicolumn{3}{|l|}{ Project Constraints } \\
\hline Functional & $\mathrm{PC} / \mathrm{F}$ & Functional or working model of presented design \\
\hline Economic & $\mathrm{PC} / \mathrm{E}$ & Project budget constraints; $\$ 20.00$ limit \\
\hline Aesthetic & $\mathrm{PC} / \mathrm{A}$ & Overall appearance of the design \\
\hline Sustainability & $\mathrm{PC} / \mathrm{S}$ & Sustainable design; use of a renewable energy source \\
\hline \multicolumn{3}{|l|}{ Course Constraints } \\
\hline $\begin{array}{l}\text { Prior Knowledge/ } \\
\text { Experience }\end{array}$ & $\mathrm{CC} / \mathrm{PK}$ & $\begin{array}{l}\text { Lack or deficiency of prior knowledge and experience } \\
\text { regarding engineering design }\end{array}$ \\
\hline Timing & $\mathrm{CC} / \mathrm{T}$ & Design artifact due dates and project deadlines \\
\hline Technological & $\mathrm{CC} / \mathrm{T}$ & $\begin{array}{l}\text { Technological concerns affecting the design project, } \\
\text { e.g. use of tablet PC }\end{array}$ \\
\hline Social & $\mathrm{CC} / \mathrm{S}$ & $\begin{array}{l}\text { Social issues affecting the design project; e.g. } \\
\text { communication and interaction of team members }\end{array}$ \\
\hline
\end{tabular}

Interview data for this study comes from a series of team semi-structured interviews approximately one hour in length with each of the four teams. The semi-structured interview format allowed the team members to think and respond generally and then elaborate with specifics or issues they felt were important. The interview protocol included questions prompting the students to think about topics regarding the conceptualization and progression of their design. Questions related to why they selected their final design solution or why, and if, their final 
design solution changed or modified throughout the design process. The main questions from the interview prompt that were the most useful for this analysis included:

- What ideas did you consider for your brainstorming inventory?

- What led you to your final design?

- What problems did you have to overcome throughout the design process?

The interviews were transcribed verbatim and then coded for the types of constraints identified in the coding scheme. The questions regarding the design process gave the researchers insight into the relationship between type of constraint and how that lead to or influenced the final decision.

\section{Results and Discussion}

We found that all teams in this study regardless of the specific final design adhered to the required project constraints of both cost/budget and utilization of renewable energy source, i.e. sustainability constraints. All teams adhered to the project constraints however the type of renewable energy did not vary greatly, e.g. solar energy and hydro energy. Teams stayed exactly at or under the $\$ 20.00$ budget constraint imposed by the requirement of the project. Table 2 specifies how each team applied the budget and renewable energy source constraint.

Table 2. Team Results for Project Constraints Economic (PC/E) \& Project Constraint Sustainability (PC/S)

\begin{tabular}{|l|l|l|}
\hline \multicolumn{2}{|l|}{ Team } & \multicolumn{2}{l|}{ Final Cost } & \multicolumn{1}{l|}{$\begin{array}{l}\text { Project/ Renewable Energy } \\
\text { Source }\end{array}$} \\
\hline 1A & $\$ 19.20$ & Solar Canopy \\
\hline 2A & $\$ 20.00$ & Hyrdo Power Bridge \\
\hline 3A & $\$ 19.15$ & Hydro Electric Urinal \\
\hline $4 \mathrm{~A}$ & $\$ 6.06$ & Collapsible Solar Cooker \\
\hline
\end{tabular}

While the type of energy source was varied across teams, two teams utilizing hydropower and two teams utilizing solar power, the reasons and methods for deciding on the final design were varied across teams. We found that teams who became fixated on cost-based constraints early in the conceptual phase kept this thread of constraints constant throughout the project and were not driven by needs, task, or functional circumstances. However teams that established core concepts for the final design used emergent constraints to guide the final solution more realistically. Table 3 shows what type of constraints were the main reasons for arriving at the final design solutions that the elaborated on during their focus group interviews.

Table 3. Primary Constraints

\begin{tabular}{|l|l|l|l|}
\hline Team & Project & $\begin{array}{l}\text { Primary } \\
\text { Constraint(s) }\end{array}$ & Example/ Data from Transcripts \\
\hline 1A & Solar Canopy & Functionality & "We chose stability and safety over cost." \\
\hline
\end{tabular}




\begin{tabular}{|l|l|l|l|}
\hline & & (DC/F) & $\begin{array}{l}\text { "Canopy requires most materials so it's } \\
\text { obviously more expensive" } \\
\text { "The canopy design can be used in a variety } \\
\text { of places, so we thought it would be better for } \\
\text { more situations." }\end{array}$ \\
\hline $2 \mathrm{~A}$ & $\begin{array}{l}\text { Hydro Power } \\
\text { Bridge }\end{array}$ & $\begin{array}{l}\text { Ethical (DC/E); } \\
\text { Functionality } \\
\text { (DC/F); Prior } \\
\text { Knowledge } \\
\text { (CC/PK) }\end{array}$ & $\begin{array}{l}\text { "One of the considerations we had for the } \\
\text { spinning water wheel was the danger to } \\
\text { wildlife." } \\
\text { "We weren't sure what to do at first because } \\
\text { of the mechanical parts in water. We figured } \\
\text { we would need to make water-proof case } \\
\text { prevents damage." }\end{array}$ \\
\hline $3 \mathrm{~A}$ & $\begin{array}{l}\text { Hydro Electric } \\
\text { Urinal }\end{array}$ & $\begin{array}{l}\text { Manufacturability } \\
\text { (DC/M); } \\
\text { Functionality }\end{array}$ & $\begin{array}{l}\text { "Source of energy comes from natural bodily } \\
\text { functions so we thought that was probably the } \\
\text { easiest." } \\
\text { "The structures are already in place so people } \\
\text { would actually considering using our design." } \\
\text { "I don't know, we were concerned about } \\
\text { using it in the weather. Like it wouldn't } \\
\text { always work on cloudy days or at night." }\end{array}$ \\
\hline 4A & $\begin{array}{l}\text { Collapsible } \\
\text { Solar Cooker }\end{array}$ & $\begin{array}{l}\text { Functionality } \\
\text { (DC/F), (PC/F) }\end{array}$ & \\
\hline
\end{tabular}

The early fixation on specific project constraints such as economic and sustainability limited the search of the conceptual space in the early stages of ideation and brainstorming. Design based constraints that emerged later in the project were addressed with less priority compared to if they had been considered in the conceptual phase, i.e. design constraints considered early in the process were more likely to be addressed and prioritized. Subsequently, design educators could use what we understand from the nature of constraints to develop activities during the early conceptual phases to overcome fixation on specific constraints; i.e. relieve specific constraints while applying others during brainstorming or ideation sessions to facilitate students in searching a broader solution space.

We would like to do further analysis of teams working through the entire process to study specific threads of constraints and their role at different stages of design. We would also like to study the importance a designer places on these categories and types of constraints to study the differences between expert and novice designers. By understanding how teams identify and leverage constraints throughout the design process and apply constraints in design situations has several implications for team learning and knowledge sharing for good conceptual design thinking and meeting design objectives. 


\section{References}

1. Dym, C. L., Agogino, A., Eris, M., O., Frey, D. D., \& Leifer, L. J. (2005). Engineering Design Thinking, Teaching, and Learning. Journal of Engineering Education, 94(1), 103-120.

2. Atman, C., Kilgore, D., \& McKenna, A. (2008). Characterizing Design Learning: A Mixed-Methods Study of Engineering Designers' Use of Language.” Journal of Engineering Education, 97(3): 309- 326.

3. ABET. (2003). Criteria for Accrediting Engineering Programs, Engineering Accreditation Commission. Baltimore, MD, 1-2.

4. NAE, (2005). Educating the Engineer of 2020, National Academy of Engineering publication.

5. Dym, C.L. \& Little, P. (2009). Engineering Design; A Project Based Introduction. 3rd Edition, New Jersey: John Wiley \& Sons, Hoboken.

6. Goel, V. \& Pirolli, P. (1992). The Structure of Design Problem Spaces. Cognitive Science, 16(3), 395-429.

7. Mehalik, M. M., \& Schunn, C. D. (2006). What constitutes good design? A review of empirical studies of the design process. International Journal of Engineering Education, 22(3), 519-532.

8. Ullman D.G. 1992). The Mechanical Design Process, NewYork: McGraw-Hill

9. Dabbeeru, M. M., Mukherjee, A. (2007). Functional design for part families of mechanical assembiles. In Hu, G. (ed)., ISCA, 263-268.

10. Sim, S.K., Duffy, A.H.B. (2003). Towards an ontology of generic engineering design activities, Research in Engineering Design, 14, 200-22.3 